\title{
Non-surgical management of intracranial subdural hematoma complicating spinal anesthesia
}

\author{
M.T. Verdú; J.F. Martínez-Lage*; B. Alonso; J.L. Sánchez-Ortega and A. Garcia-Candel
}

Services of Anesthesiology and Neurosurgery*. Hospital Universitario Virgen de la Arrixaca. Murcia. Spain.

\section{Summary}

We report the case of a 29 year-old woman who presented a symptomatic intracranial subdural hematoma developing shortly after spinal anesthesia.

The patient was fully conscious at clinical onset, and thus we treated her conservatively with an epidural autologous blood patch and close neurological observation. Given the clinical improvement the possibility of surgery was discauded in agreement with the neurosurgical team.

Most cases of subdural hematoma appearing after spinal anesthesia are treated with surgery. In the present case the subdural hemorrhage was detected at our hospital 20 days after the anesthetic procedure, and given the excellent state of consciousness, we choosed a conservative management.

KEY WORDS: Complications. Epidural blood patch. Magnetic resonance imaging. Postdural puncture headache. Subdural hematoma.

Manejo no quirúrgico de hematoma subdural intracraneal tras anestesia espinal complicada

\section{Resumen}

El hematoma subdural (SDH) es una complicación evolutiva rara, documentada y de riesgo vital en los cuadros de cefalea post punción subdural (PDPH). Presentamos un caso de esta rara complicación resuelto con un parche de sangre autóloga epidural y tratamiento conservador, sin precisar evacuación quirúrgica.

PALABRAS CLAVE: Resonancia magnética. Cefalea postural. Hematoma subdural. Complicación. Parche epidural hemático.

Recibido: 19-09-05. Aceptado: 16-02-06

\section{Introduction}

Subdural hematoma (SDH) is a rare but, documented and life-threatening complication after dural punctures often manifested by post-dural puncture headache $(\mathrm{PDPH})^{1,6}$. We report a case of this uncommon complication resolved through autologous epidural blood patch (EBP) and conservative treatment without the need for surgical drainage.

\section{Case description}

A 29-year old woman was admitted to our neurosurgery department presenting with expressive dysphasia and complaining of headache and numbness in her upper right limb and face. She had undergone an emergency cesarean section for acute fetal distress while under subarachnoid anesthesia in another hospital 20 days prior to admittance in our hospital. The patient's pregnancy had evolved normaly, having received the routine prenatal care.

The patient had no history of a neurological or blood disease, migraine, cancer or infection. No antecedent of head injury before or after the spinal anesthesia was reported. She denied the intake of cronic treatment or using tobacco, alcohol, or street drugs. Her history revealed an allergy to pyrazolone.

While undergoing spinal anesthesia the patient appeared anxious, and the anesthesiologist encountered technical difficulties with needle insertion. On a second attempt a subarachnoid puncture at L2-L3 level was achieved with a 26-gauge needle, pencil-point (Sims Portex Limited, Hythe, Kent, UK). The anesthetic level was appropriate with hyperbaric bupivacaine $0.5 \%$ (10 mg) plus $15 \mu \mathrm{g}$ of fentanyl. Surgery elapsed uneventfully.

Twelve hours after the procedure, the patient complained of an intense generalized headache that got worse upon sitting upright. No fever or signs of meningeal irritation

Abbreviations. CSF: cerebrospinal fluid. EBP: epidural blood patch. PDPH: post dural puncture headache. SDH: subdural hematoma 


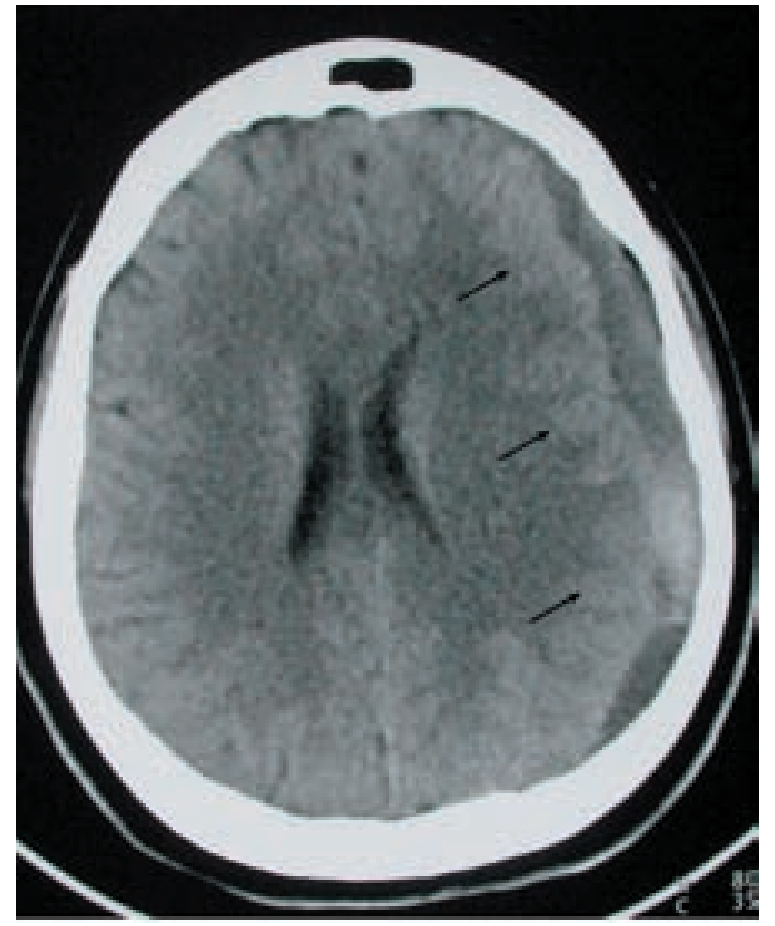

Figure 1. Cranial computed tomography scan showing frontal parietal subdural hematoma (subacute or chronic) with inner hyperdense area of recent bleeding. Very mild mass effect on the midline, ventricles, and adjacent cortical sulci.(blacks arrows).

were noted. A diagnosis of PDPH was made and accordingly, she was given analgesics, oral hydration, and bed-rest. By the fourth day, the patient showed a sligth improvement and was discharged home.

Twenty days later the patient was brought to the emergency department of our hospital complaining of severe headaches that was not relieved by lying down, and numbness in her upper rigth limb and face. On examination, the patient was afebrile, alert and orientated but showed expressive dysphasia. No papilloedema was detected upon eye examination.

Coagulation tests and complete blood count, including platelets and white blood, where within normal range.

A plain cranial computed tomography (CT) and a emergency gadolinium-enhanced cranial and lumbar MRI revealed an extensive left frontal - temporo- parietal SDH with scattered areas of acute and subacute supratentorial hemorrhage and lumbar meningeal thickening without evidence of cerebrospinal fluid (CSF) fistula (figures 1,2 and 3 ). Upon consultation with neurosurgery and given the good neurological health status of the patient, it was decided not to surgically evacuate the collection but rather maintain a "wait and watch" approach, initiate medical treatment, and perform a lumbar autologous EPB. Blood

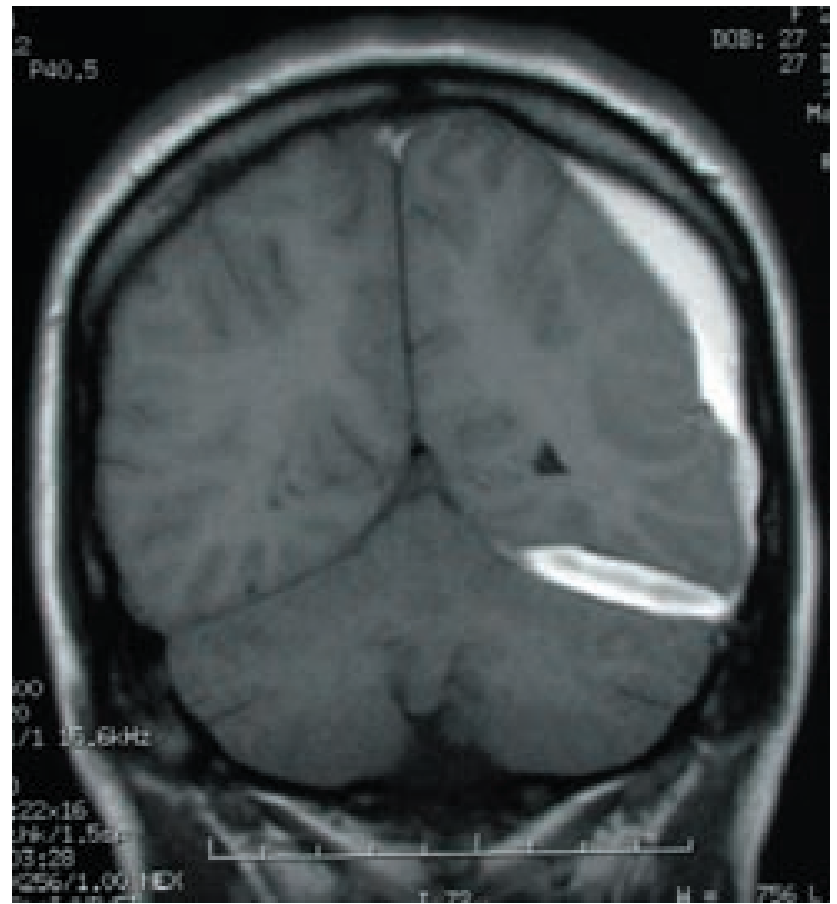

Figure 2. Coronal T1-weighted MRI: hyperintense hematoma in the subdural wall and the tentorium cerebelli (subacute or with evident chronicity) with mass effect on cortical sulci.

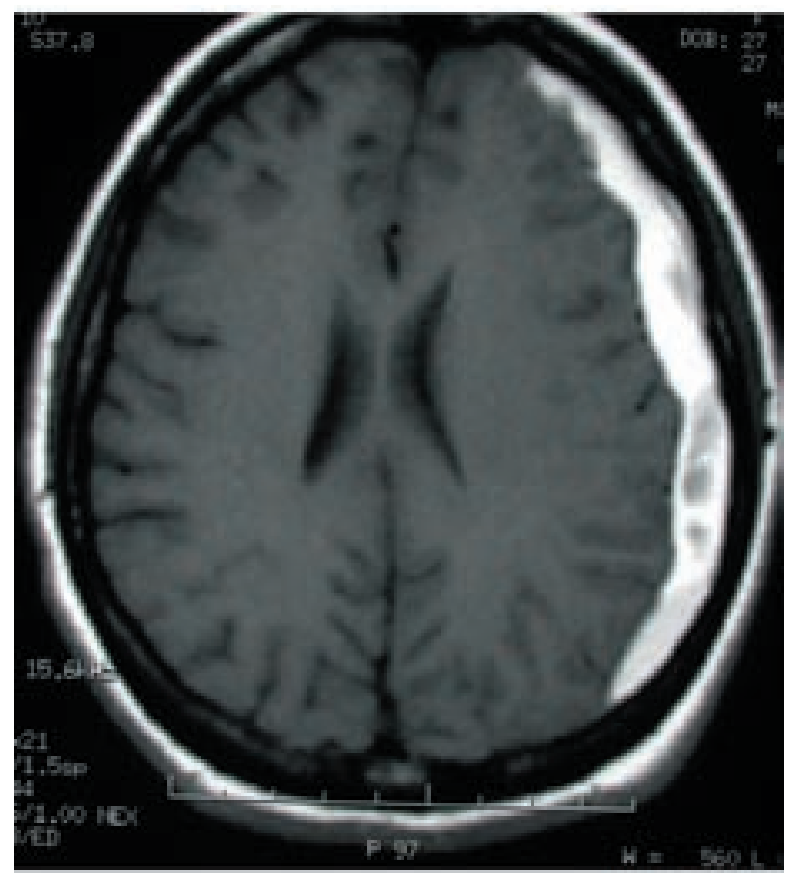

Figure 3. Axial T1-weighted MRI of hyperintense crescentshaped hemorrhage with isointense areas due to subacute hematoma and inner areas of acute bleeding. Very mild mass effect on the midline, ventricles, and cortical sulci is visible. 


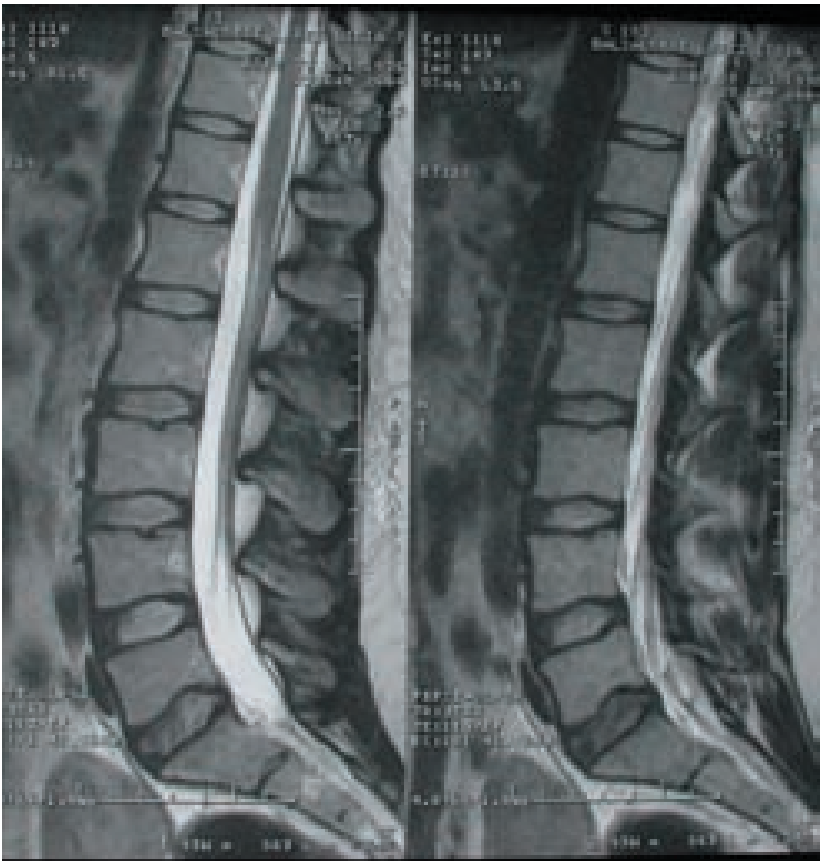

Figure 4. Sagittal T1-weighted gadolinium-enhance MRI of the lumbar spine: enhancement of a cauda equina nerve root is seen.

cultures were obtained, and 12 hours after admission an EPB was performed under sterile conditions with $17 \mathrm{~mL}$ of autologous blood at L3-L4 level using an 18-gauge Tuohy needle. No complications arose. The patient remained in the intensive care unit for close neurological monitoring.

Treatment consisted of analgesics, hydration, dexamethasone (4 mg t.d.s.), and strict bed-rest. The patient's condition gradually improved, her previous dysphasia and numbness completely disappeared during the first week. She was discharged home at day 15 with mild headache, and a follow-up cranial CT demonstrated near resolution of the SDH, no midline shift, and ventricular re-expansion (Figure 5). A cranial CT performed at day 30 after diagnosis was reported as normal (Figure 6).

\section{Discussion}

According to the literature, cases of intracraneal SDHacute, subacute, or chronic- secondary to dural punctures have mainly been treated through surgery, especially if focal neurological deficits have been detected. The neurosurgery department in our hospital opted for conservative treatment. Our anesthesiology department suggested to perform a lumbar autologous EBP as a posible means to stop the CSF leakage as the primary cause triggering the patient's clinical picture as well as any resulting persistence.

Recent publications ${ }^{3,4}$ suggest that an EBP does not reliably prevent SDH development when performed after

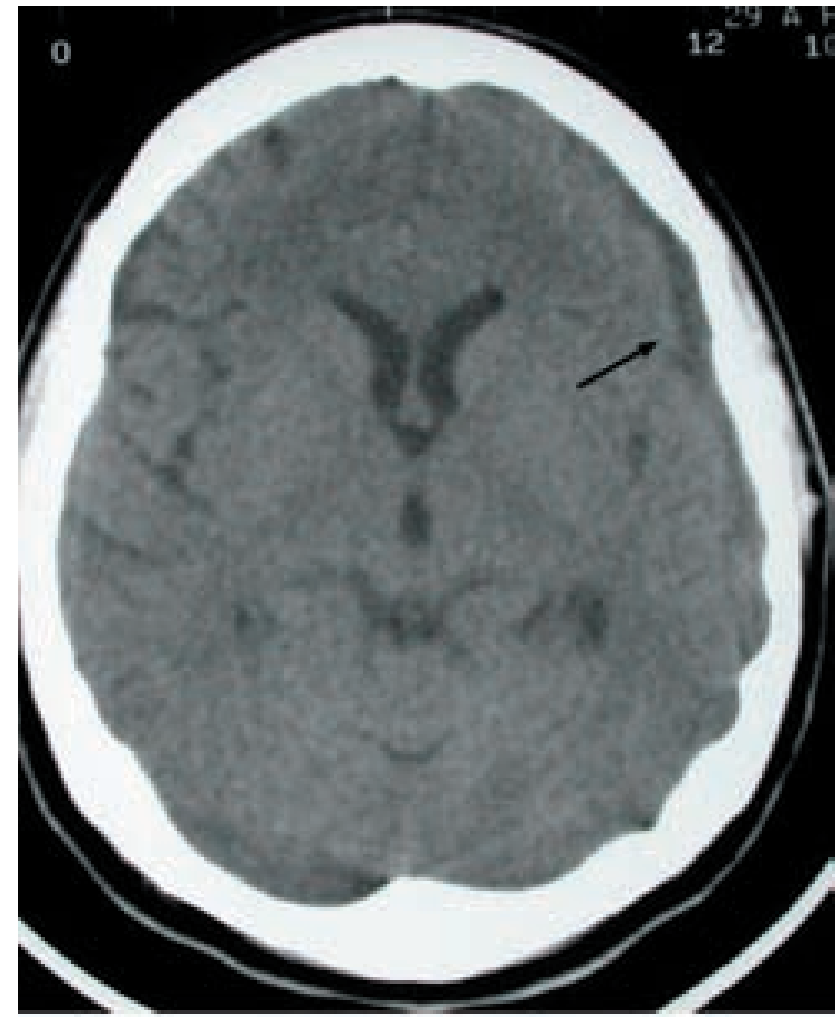

Figure 5. Plain computed tomography scan 15 days after diagnosis: almost complete resolution of the subdural hematoma with centered midline and ventricular reexpansión (blacks arrow).

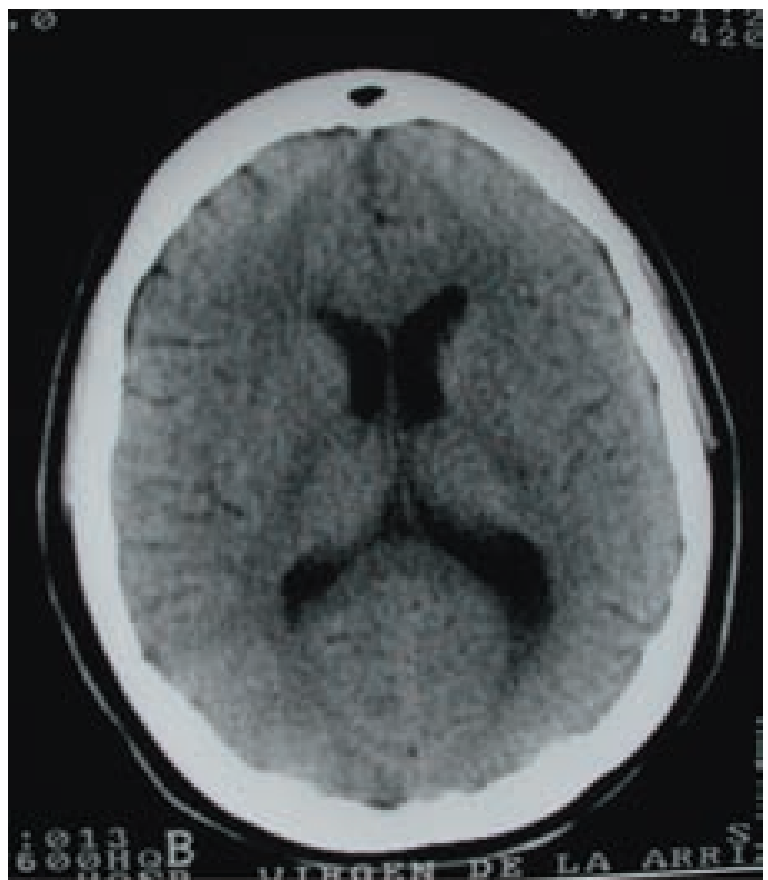

Figure 6. A normal plain cranial computed tomography scan. 
the onset of the clinical symptoms secondary to intracranial hypotension.

The CT and gadolinium-enhance cranial and lumbar MRI images of our patient showed a large subacute left fronto-temporo-parietal and supratentorial hematoma with images of acute rebleeding that produced a minimal midline shift (Figure 1 and 2).

The presence of an intracraneal space-occupying lesion with accompanying raised intracraneal pressure should be ruled out if an EBP is to be performed.

The gadolinium-enhance MRI of our patient suggested indirect signs of meningeal thickening consistent with intracranial hypotension secondary to a persistent fistula in the dura mater causing CSF loss, although there was no neuroimaging confirmation ${ }^{7,10}$. (Figure 4).

The mecanism responsible for subdural hygromas or hematomas is persistent CSF leakage through the dura mater after lumbar puncture; subsequent cerebral hypotension with caudal displacement of the shifting brain structures in turn causes subdural veins to stretch and tear ${ }^{9,5}$.

Over time features of persistent PDPH change and/or reappear later and may be accompanied with new neurological symptoms. We consider it essential to establish a differential diagnosis as early as posible to rule out other posible causes (PDPH, migraine, pregnancy-induced hypertension, meningitis, brain tumors, subarachnoid hemorrhage, SDH, cerebral venous thrombosis, or nonspecific causes $^{8}$ ), to prevent serious and life-threatening complications such as those in our patient. We strongly recommend the early collaboration between neurosurgery and anaesthesiology departments in deciding the most appropriate management option, whether it be surgery or conservative. The epidural autologous blood patch ${ }^{2}$ and conservative treatment should also be considered as valid and less aggresive alternative therapy in cases of postdural puncture SDH. Close observation of the patients' neurological evolution seems to be mandatory.

\section{References}

1. Acharya, R., Chabra, S.S., Ratra, M., Sehgal, A.D.: Cranial subdural haematoma after spinal anaesthesia. Br J
Anaesth 2001; 86: 893-895.

2. Barbara-Scavone, B.M., Wong, C.A., Sullivan, J.T., Yaghmour, E., Sherwani, S.S., McCarthy, R.J..: Efficacy of a prophylactic dural puncture patch in preventing post dural puncture headache in parturients after inadvertent dural puncture. Anesthesiology 2004; 101: 1422-1427.

3. Davies, J.M., Muphy, A., Smith, M., O’Sullivan, G.: Subdural haematoma after dural puncture headache treated by epidural blood patch. Br J Anaesth 2001; 86: 720-723.

4. Diemunsch, P., Balabaud, V.P., Petiac, C., et al.: Bilateral subdural hematoma following epidural anesthesia. Can J Anaesth 1998; 45: 328-331.

5. Lee, K.S.: The pathogenesis and clinical significance of traumatic subdural hygroma. Brain Inj 1998; 12: 595603.

6. Macon, M.E., Armstrong, L., Brown, E.M.: Subdural hematoma following spinal anestesia. Anesthesiology 1990; 72: $380-381$.

7. Reina, M.A., Alvarez-Linera, J., López, A., BenitoLeón, J., De Andrés, J.A., Sola, R.G.: Applicationsss of magnetic resonance imaging to postdural puncture headache in patients with cerebrospinal fluid hypotension. Rev. Esp. Anestesiol. Reanim. 2002; 49: 89-100.

8. Stocks, G.M., Wooller, D.J., Young, J.M., Fernando, R.: Postpartum headache after epidural blood patch: investigation and diagnosis. Br J Anaesth 2000; 84: 407410 .

9. Verdú, M.T., Alonso, B., Burguillos, S., Martínez-Lage, J.F.: Postpartum Subdural Hygroma after Epidural Analgesia: Anesthesiology 1999; 91: 867-869.

10. Weitz, S.R., Drasner, K.: Spontaneous intracraneal hypotension: a series. Anesthesiology 1996; 85: 923925.

Verdú, M.T; Martínez-Lage, J.F.; Alonso, B.; SánchezOrtega, J.L.; Garcia-Candel, A.: Non-surgical management of intracranial subdural hematoma complicating spinal anesthesia. Neurocirugía 2007; 18: 40-43.

Corresponding author: Maria Teresa Verdú Martínez. Plano San Francisco $10,1^{\circ}$ D. 30004, Murcia. Spain. 